\title{
Dipeptidyl Peptidase-4 Inhibitor
}

National Cancer Institute

\section{Source}

National Cancer Institute. Dipeptidyl Peptidase-4 Inhibitor. NCI Thesaurus. Code C98086.

Any inhibitor of the proline-specific serine protease dipeptidyl peptidase 4 (DPP-4), with hypoglycemic activity. DPP-4 inhibitors bind to DPP-4 and inhibit the breakdown of the incretin hormones glucagon-like peptide-1 (GLP-1) and glucose-dependent insulinotropic polypeptide (GIP). This prolongs incretin activity, increases postprandial insulin release, decreases glucagon release, delays gastric emptying and lowers blood glucose levels. The risk for hypog lycemia is neg ligible with the use of DPP-4 inhibitors. 